\title{
Fault Diagnosis of Rotating Electrical Machines Using Multi-Label Classification
}

\author{
Adrienn Dineva ${ }^{1}$, Amir Mosavi ${ }^{1,2, * \mathbb{D}}$, Mate Gyimesi ${ }^{1}$, Istvan Vajda ${ }^{1}$, Narjes Nabipour ${ }^{3, *(D)}$ and \\ Timon Rabczuk 4 \\ 1 Institute of Automation, Kalman Kando Faculty of Electrical Engineering, Obuda University, 1034 Budapest, \\ Hungary; dineva.adrienn@kvk.uni-obuda.hu (A.D.); mate.gyimesi@generalmechatronics.com (M.G.); \\ vajda@uni-obuda.hu (I.V.) \\ 2 Institute of Structural Mechanics, Bauhaus Universität-Weimar, D-99423 Weimar, Germany \\ 3 Institute of Research and Development, Duy Tan University, Da Nang 550000, Vietnam \\ 4 Department of Computer Engineering, College of Computer and Information Sciences, King Saud \\ University, Riyadh 12372, Saudi Arabia; timon.rabczuk@uni-weimar.de \\ * Correspondence: amir.mosavi@kvk.uni-obuda.hu (A.M.); narjesnabipour@duytan.edu.vn (N.N.)
}

Received: 10 October 2019; Accepted: 21 November 2019; Published: 25 November 2019

check for updates

\begin{abstract}
Fault Detection and Diagnosis of electrical machine and drive systems are of utmost importance in modern industrial automation. The widespread use of Machine Learning techniques has made it possible to replace traditional motor fault detection techniques with more efficient solutions that are capable of early fault recognition by using large amounts of sensory data. However, the detection of concurrent failures is still a challenge in the presence of disturbing noises or when the multiple faults cause overlapping features. Multi-label classification has recently gained popularity in various application domains as an efficient method for fault detection and monitoring of systems with promising results. The contribution of this work is to propose a novel methodology for multi-label classification for simultaneously diagnosing multiple faults and evaluating the fault severity under noisy conditions. In this research, the Electrical Signature Analysis as well as traditional vibration data have been considered for modeling. Furthermore, the performance of various multi-label classification models is compared. Current and vibration signals are acquired under normal and fault conditions. The applicability of the proposed method is experimentally validated under diverse fault conditions such as unbalance and misalignment.
\end{abstract}

Keywords: multiple fault detection; rotating electrical machines; drive systems and power electronics; multi-label classification; machine learning; data science; big data; energy conversion; soft computing; fault severity; fault classifiers; electric machine

\section{Introduction}

Rotating electrical machines are responsible for converting a great amount of worldwide energy into mechanical energy [1]. Mobility, transportation, logistics, construction, production, agriculture, food, automation, and basically any economic activity and industry directly or indirectly depend on rotating electrical machines, as discussed in literatures, e.g., [2-6]. The rapidly evolving industries have suggested that we will be witnessing a further increase in this rate [7]. Furthermore, the increasing demand for hybrid and electric vehicles, the rapid transition toward automated systems and micro and nano mechatronics devises, increasing interests for more efficient energy conversion systems, and emerging new robotics machines have been motivating further advancement in the rotating electrical machines reported in the works of scholars, e.g., [7-18].

One of the key factors of overall efficiency maximization covers the well-sized and high-efficient components [19-22]. Therefore, the reduction and prediction of faults occurring in electrical machines 
and drive systems such as electrical, thermal, and mechanical faults of electrical machines are strongly suggested to be essential [23-29]. Classical solutions of Fault Detection and Diagnosis (FDD) [30] are based on the complex mathematical models, e.g., supervised diagnosis [25-29,31], or dynamic models [32-37] of the processing system. Intelligent modernization has contributed to the widespread use of Machine Learning (ML) techniques in industrial applications [38-43]. As a result, the latest FDD systems demand more artificial intelligent solutions to incorporate multiple fault events or dynamically changing load profiles in case of incomplete or noisy measurements [44-49]. Commonly, the diagnosis and predictions are calculated through motor current signature analysis (MCSA) [50,51], i.e., examining the output signals of the motor stator's current while running on a steady-state operating mood [52-56]. MCSA analyses the time-frequency decomposition of the current signals or by faults' frequencies in the frequency domain. MCSA works based on a single input source and representing a simple, low-cost and non-invasive monitoring method [50,57,58]. An enhanced method of MCSA in the case of multiphase electrical machines is called electrical signature analysis (ESA) [59].

A timely diagnosis of the complete rotating machinery system contributes to avoiding overpriced reparations and unexpected breakdowns. According to [60], the great majority of recent electric motor condition monitoring methods can be classified into three main categories. The first-class includes the detection of single faults by analyzing one or multiple parameters; the second class covers the detection of different faults with multiple parameters and processing techniques, and the last one contains the mixed techniques of various computing-intensive approaches to analyze different electrical and mechanical parameters in order to detect multiple faults [61-64]. In contrast to conventional signal processing based fault detection techniques [65], recently a few attempts were made for the application of intelligent algorithms [66,67] including new approaches to Fault Detection and Isolation (FDI) [68] based on fuzzy logic, decision trees, neural networks, and further machine learning techniques [69-73]. However, most of them rely on the measurement and processing of vibration signals, which require at least one vibration sensor, which demands extra costs for its proper installation and maintenance [74-77]. In addition, a technician needs knowledge and a good amount of experience to correctly use such sensors [78-84]. However, the ESA reported being able to reveal a large number of relations between the machine parameters [85-88]. Therefore, the ML techniques are highly suitable to support the processing of such extracted information.

There are some intelligent methods that have evolved in recent years with the purpose of improving fault diagnosis methods of electrical motor and drive systems associated with various fault events on the basis of current or vibration signature analysis. For instance, in [89] it has been shown that motor current signature analysis based Support Vector Machine classifier achieves better accuracy in case of gearbox multiple fault detection than decision trees. In [90], the authors state that hybridization of machine learning methods, e.g., adaptive neuro-fuzzy inference system (ANFIS) in combination with Classification and Regression Tree (CART) has the potential for fault diagnosis of induction motors. The proposed method also employs vibration and current signals and achieves nice performance; however, the method lacks the flexibility to easily fit with specific types of machines. Random Forest (RF) classifier was developed for multi-class bearing faults in [91]. This work also employs input features extracted from vibration signals. Worth mentioning that the bearing fault is an important source of faults in the rotating electrical machines that has been modeled by machine learning methods. Wardle [92] and Lynagh et al. [93] provide extended description on the causes of the bearing fault.

A number of studies report the advantages of the wavelet transform in signal detection and fault feature identification (see, e.g., [94-96]). The decision tree's capability, in combination with the well-studied wavelet technique, also provides a possible tool for fault detection [97]. In [97], a large number of possible wavelets are analyzed in order to find the best match. The selection of a suitable wavelet function is still a challenge for the users for specific applications. The investigation of mechanical fault signatures of misalignment and unbalance is carried out in [97], where the authors found that a multilayer perceptron model only with three layers, can classify the faults. High accuracy 
is reported that is achieved by training the network on a large dataset. In [98] a Convolutional Neural Network $(\mathrm{CNN})$ is successfully applied for fault classification. This approach relies on the S-transform of vibration signals into images displaying the time-frequency patterns in which the pattern recognition is performed. We can clearly observe that the common pattern recognition methods are relying on the assumption of a single fault scenario, and only a limited number of work proposes flexible and comprehensive solutions for multiple fault detection. In the presence of multiple faults, the single fault recognition techniques' performance may be degraded. In addition, the other machines operating in the motor's environment or the coupled subsystems, etc., may introduce further noise components in the measured signal. As a result, it may occur that one of the faults or noise components obscures a particular fault feature and makes it impossible to recognize it. Its further consequence is that the fault isolation operations may become rather difficult.

However, the above brief literature review shows that only a few studies have been published on the investigation of the multilabel prediction performance of recent classifier algorithms in the presence of disturbing noises in the case of electrical signature analysis. One of the major drawbacks from adopting these algorithms to ESA based motor diagnoses is that they require a large training set, which is difficult and time-consuming to collect. In addition, each individual electrical machine and drive system would require their own type- and operation-specific pattern fault library. The feature extraction step raises further questions. The performance of a classifier strongly depends on the effectiveness of the features representing the patterns of different fault events. In the case of fault diagnosis of electrical machines, the knowledge about the physical system may limit the number of necessary features. Furthermore, in engineering practice, there is still considerable ambiguity concerning the selection of the most suitable classifier.

Based on the above briefly summarized antecedents and state-of-the-art applications, this research on the development of new condition monitoring and diagnostic methodology for electrical machines and drives is focused into the applicability of improved versions of multi-label classification machine learning approaches for multiple fault detection under noisy conditions and also the simultaneous determination of fault severity. The contribution of this work is to reveal the most suitable multi-label classification methodology for simultaneously diagnosing multiple faults and evaluating the fault severity under noisy conditions. For this purpose, the performance of various multi-label classification models is compared. Some observations indicate that numerous attributes result in wide parameter space. In our view of the physical model approach, we highlight the important features to be extracted. Current and vibration signals are acquired under normal and fault conditions on an experimental set-up. To enable fast training set preparation, we propose a semi-synthetic database based on a small number of measurements.

The rest of this paper is organized as follows: in Section 2, we briefly introduce the latest multi-label classification methods, and we derive a new methodology for multi-fault diagnosis and severity assessment for rotating electrical machines and drive systems. Section 3 is devoted to the description of the experimental setup as well as the description of feature extraction and dataset preparation. Section 4 presents the results of our investigations on the multi-label classification methods. After, in Section 5 we draw some pertinent conclusions.

\section{Multiple Fault Classification and Fault Severity Determination}

\subsection{Brief Introduction of Multi-Label Classification Methods}

Modern industry requires data mining algorithms that are able to efficiently cope with the growing amount of information and large datasets. Specialized processing tasks of various practical application fields deal with common characteristics of the stored data that can be assigned to multiple categories $[99,100]$. Therefore, multi-label classification algorithms have gained increasing interest in recent years. Specialized techniques for learning such type of data, which have the capability of predicting a set of relevant labels for new species, are still the focus of researches. Currently, three main 
groups of newly developed multi-label classification methods are proposed in the literature, namely the data transformation methods, adaptation methods, and ensemble of classifiers [101,102]. Early solutions for multi-label classification methods cover the data transformation techniques. The concept is to turn the original multi-label set into binary sets or multi-class sets that adequately can be processed with the classical algorithms. Besides binarization with the widely applied binary relevance technique, also the voting methods and divide-and-conquer approaches are applied to accomplish multi-label transformation $[100,103,104]$. Such separated sets are learned by single-label classifiers, such as decision trees. This group also includes the Classifier Chains that are similar to the binary relevance technique but perform the binarization in consecutive classifiers, since the models' order has importance $[105,106]$. The output of one response variable for a sub-classifier is used as an additional feature in the next sub-classifier. The optimal order of the classification models can be enhanced by the Naïve Bayes method.

Adaptation methods are based on the adaptation of conventional classification methods to multi-label versions without problem transformation. The adaptation methods are extensions of well-founded automatic classification algorithms. For instance, the support vector machine (SVM) classifiers [107], the k-nearest neighbors (KNN) [108], or temporal classifiers [109] are able to predict binary or multiclass outputs simultaneously $[110,111]$. KNN is a non-parametric method used for classification and regression [112,113]. In KNN, an object is classified through a plurality vote of its neighbors while the object assigned to the class of the most common $\mathrm{k}$ nearest neighbors. $\mathrm{K}$ is a positive and small number, to be able to reduce the number of calculations, and thus the process duration. Similarly, the neural networks and decision trees have such abilities, but the adaptation of the algorithm may become difficult. Ensemble classifiers are also held notable interest. The KNN employs an euclidean distance function $\left(D_{r t}\right)$ as follows:

$$
D_{r t}=\sqrt{\sum_{i=1}^{m} W_{i}\left(x_{i r}-x_{i t}\right)^{2}, t=1,2, \ldots, n}
$$

where $W_{i}(i=1,2, \ldots, m)$ is the weight of predictors. $D_{r t}$ estimates the neighborhood of the prediction value $X_{r}=\left\{x_{1 n}, x_{2 n}, x_{3 n}, \ldots, r\right\}$ in real-time using former observation value of $X_{t}=\left\{x_{1 b}, x_{2 b}, x_{3 b}, \ldots, x_{m r}\right\}$. The classification ensemble approach is based on the aggregation of the outputs of a number of the individual classifier by weighted or unweighted averaging [114]. According to the 'no-free-lunch' theory $[115,116]$, it is assumed that the weaker classifiers with different biases can achieve better performance than the better ones $[114,117,118]$.

\subsection{The Scheme of the Proposed Method}

We mainly focus on diagnostics based on Electrical Signature Analysis, but we also utilize traditional vibration data. The analysis starts with the elimination of the components that do not contribute to the system from the acquired stator phase current signals. After, the filtered signal is used for extracting the fault features affecting the machine health. Then, the trained multi-label classifier receives the new feature vectors and performs the multi-label prediction. The flowchart of the method is depicted in Figure 1 below. 


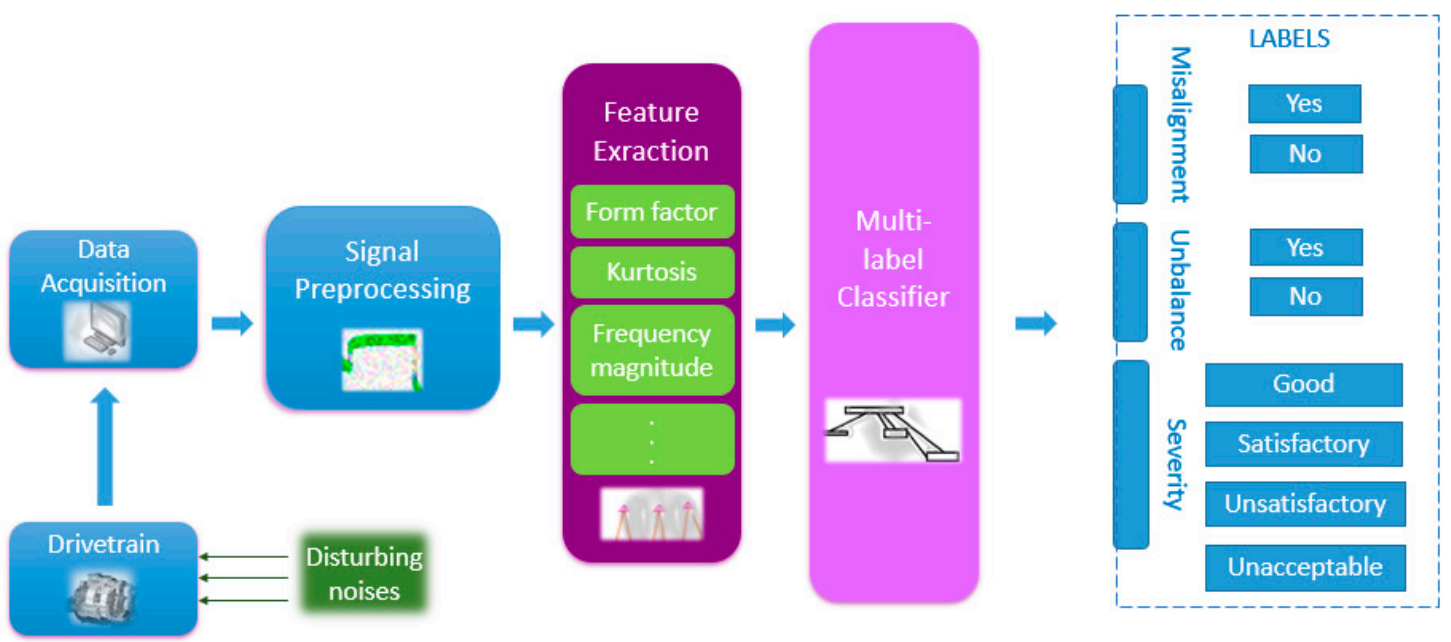

Figure 1. Flowchart of the proposed multi-label fault diagnosis system.

For both of the misalignment and unbalance faults, the two targets can be treated as logical labels, i.e., each output is a binary value, indicating whether a label is associated with the fault or not.

For evaluating the fault severity, we can inject additional classes or alternatively we can generate a second classifier that is executed parallel. Acquired vibration data is sufficient for proper evaluation. The fault severity can be determined easily according to the ISO 2372 Standard [119,120] for vibration severity of machines operating between 600 to $1200 \mathrm{rpm}$ range. The severity classes are shown in Table 1.

Table 1. Vibration severity per ISO (International Organization for Standardization) 10816.

\begin{tabular}{|c|c|c|c|c|}
\hline $\begin{array}{c}\text { Vibration Velocity } \\
{[\mathrm{mm} / \mathrm{s}]}\end{array}$ & $\begin{array}{c}\text { Class I. Small } \\
\text { Machines }\end{array}$ & $\begin{array}{c}\text { Class II. Medium } \\
\text { Machines }\end{array}$ & $\begin{array}{c}\text { Class III. Large } \\
\text { Rigid Foundation }\end{array}$ & $\begin{array}{l}\text { Class IV. Large } \\
\text { Soft Foundation }\end{array}$ \\
\hline 0.28 & \multirow{2}{*}{\multicolumn{4}{|c|}{ GOOD }} \\
\hline 0.45 & & & & \\
\hline \multicolumn{5}{|l|}{0.71} \\
\hline \multicolumn{5}{|l|}{1.12} \\
\hline \multicolumn{5}{|l|}{1.80} \\
\hline 2.80 & \multicolumn{4}{|c|}{ SATISFACTORY } \\
\hline \multicolumn{5}{|l|}{4.50} \\
\hline 7.71 & \multicolumn{4}{|c|}{ UNSATISFACTORY } \\
\hline \multicolumn{5}{|l|}{11.20} \\
\hline \multicolumn{5}{|l|}{18.00} \\
\hline 28.00 & \multirow{2}{*}{\multicolumn{4}{|c|}{ UNACCEPTABLE }} \\
\hline 45.90 & & & & \\
\hline
\end{tabular}

\section{System Description and Experiment}

\subsection{System Description}

The outlined method requires precise measurements and an appropriate dataset. The theoretical considerations and their usability are validated by simulation investigations by using the collected data on the test bench. The Laboratory of Electrical Machines of the Institute of Automation provides equipment for motor diagnostics and expert system development that allows the integration of measurement, computing, and communication. The laboratory has a wind power simulation system, where the wind power is simulated by an inverter-driven cage induction machine (Leroy Somer 3fFLSE225M-TC; No28221L12001/2012; IP55IK08; P = $30 \mathrm{~kW} ; n=985$ 1/min; U = 230/400 V; f = 50 Hz; $\cos \varphi=0.82)$. Three different types of motors are available on the test bench: one brushless synchronous machine of $40 \mathrm{~kW}$, one double-fed asynchronous machine, and one permanent magnet 
synchronous machine (PMSM) (Leroy Somer 3fLSRPM200L-T; No728333K12001/2012; IP55IK08; P $=40 \mathrm{~kW} ; n=15001 / \mathrm{min} ; \mathrm{U}=400 \mathrm{~V} ; \mathrm{f}=100 \mathrm{~Hz} ; \mathrm{I}=83 \mathrm{~A} ; 95.2 \%$; Imax $/ \mathrm{In}=145 \%$ ) on which the measurements and tests are carried out (see, Figure 2).

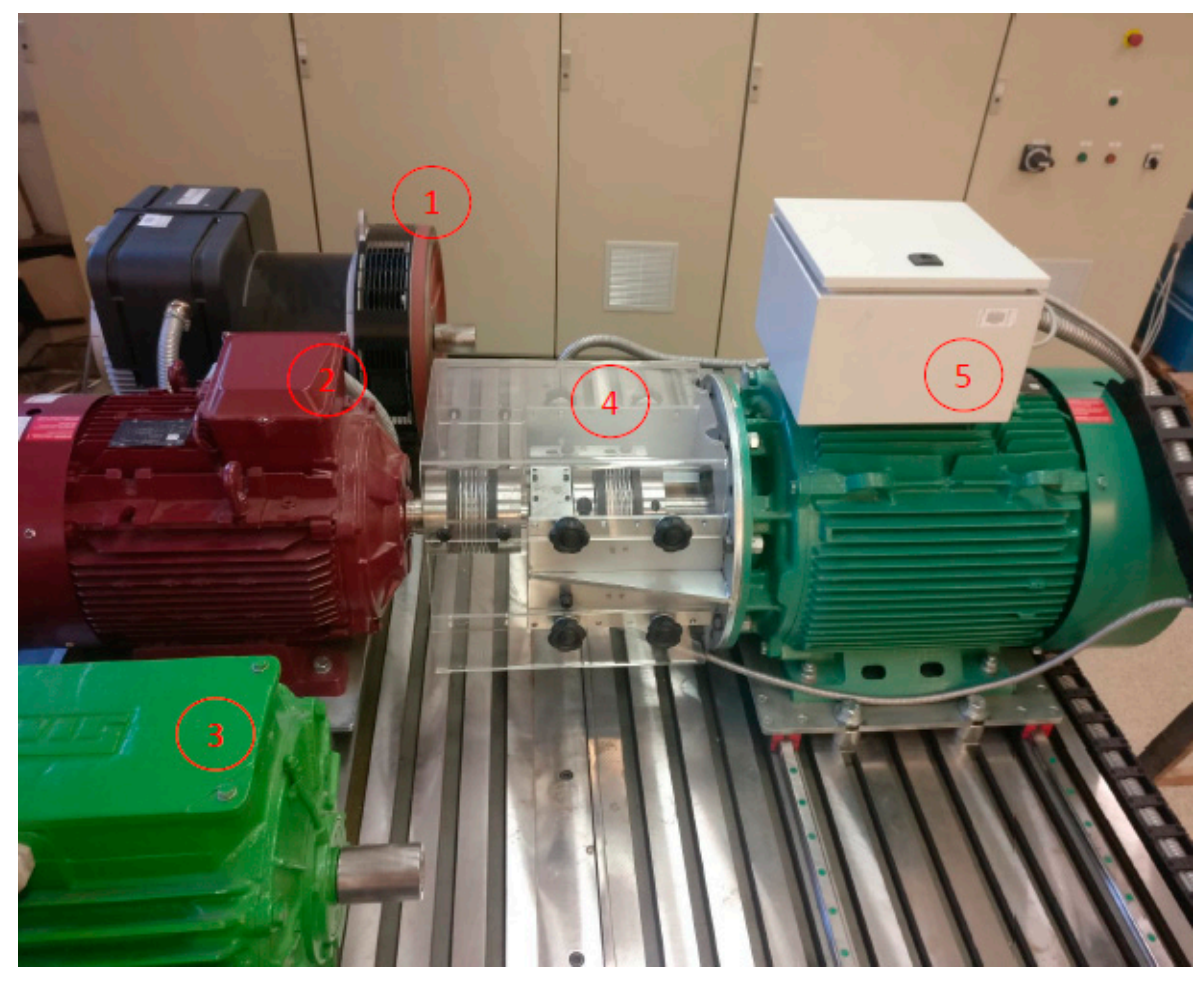

Figure 2. The test bench; (1) brushless motor, (2) permanent magnet synchronous motor, (3) double fed asynchronous motor, (4) coupling; Bellows shaft coupling connects the generator and the motor, (5) inverter-driven cage induction machine.

The system is capable of simulating fault events. Misalignment and unbalance are introduced in the system, and a simple NI data acquisition system for data collection purposes is installed. The laboratory has the latest NI LabVIEW Software. The data acquisition system consists of the National Instruments PCI 6013 B-Series 16-Analog-Input multifunction DAQ board and the SC-2345 signal conditioning connector block with various modules and sensors connected to the test bench. The representation of the data acquisition system through the visualization of block schematic illustration is available in Figure 3.

The measuring and controlling LabVIEW software collaborates with the above-presented devices and additional hardware components and conducts the measurements. The measurement data are processed simultaneously on each channel, which takes a relatively short time. The LabVIEW software is developed in order to inspect the proper configuration of the test bench. The software displays the amplitude-time signals of the three-phase stator current and vibration signals of the motor and the generator in real-time. The second tab of the software views the Park Vector's spectrums calculated from the current signals. Frequency-amplitude diagrams can be used to predict machine errors during measurement. The third part of the program saves the measurement results in the Excel.csv format, so the measured values can be evaluated and processed later. 


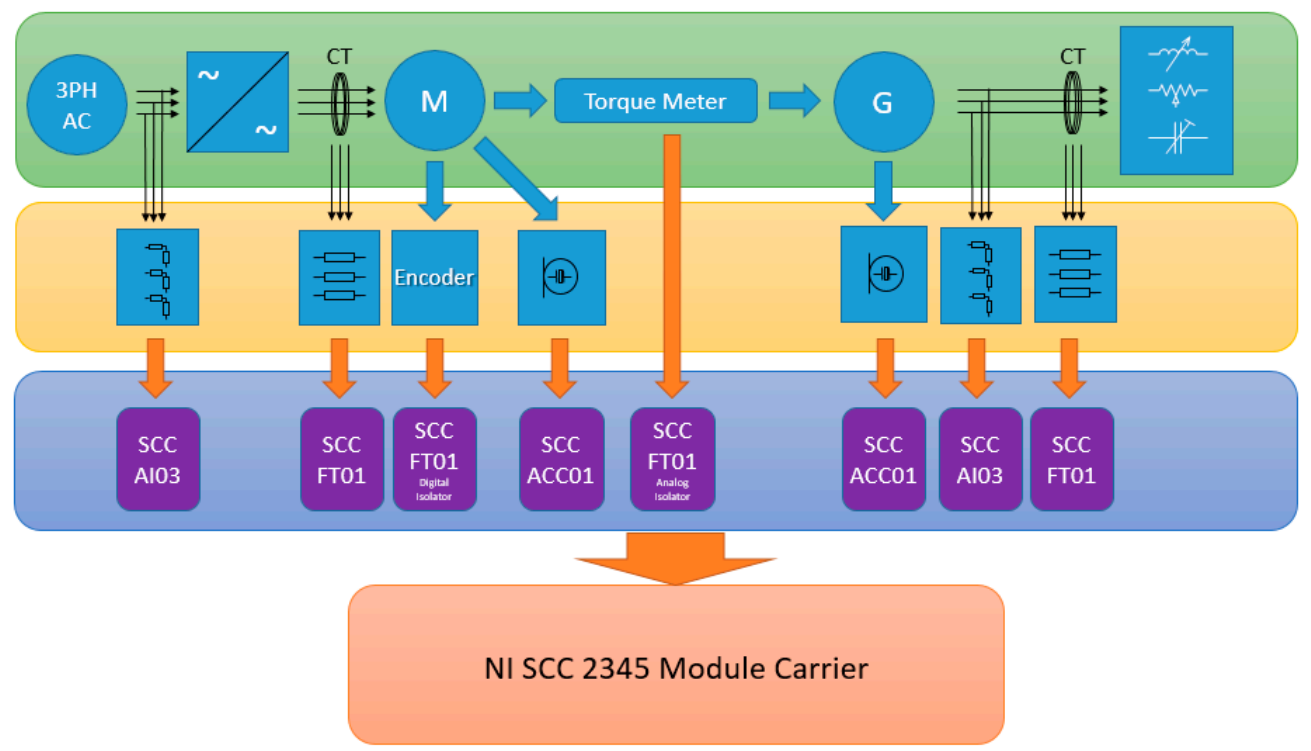

Figure 3. Block scheme of the data acquisition system.

\subsection{Feature Extraction and Dataset Preparation for Training}

Stator current signals and vibration data picked for fault-free no load and $40 \%$ load of full load at the speed of $1500 \mathrm{rpm}$ conditions with $\mathrm{fs}=10000$ sampling rate and $\mathrm{t}=20 \mathrm{~s}$ duration in the presence of both mechanical faults. Unbalance results in high-frequency amplitudes at frequencies at once the rotational speed. The typical fault features of misalignment are dominant frequencies at one or two times the rotational speed depending on the degree of angular misalignment and the type of the couplings. Spectral images also display sub-harmonic multiplies of 1/2xRPM. However, the different speeds, loads, motor parameters, and operational setups, etc., may affect the fault frequencies. Differences between faulty and healthy conditions can immediately be observed from vibration spectra during the measurement (see Figure 4).

It is clearly visible in the spectrum that the machine vibrates strongly around $25 \mathrm{~Hz}$, which indicates a shaft misalignment. From the generator current spectrum, a $50 \mathrm{~Hz}$ component appeared in the spectra, while in the motor current spectrum a $75 \mathrm{~Hz}$ component (see Figure 5). The reason is that a generator is a 4-pole machine, while the motor has six poles. This indicates exactly that the machine vibrates at $25 \mathrm{~Hz}$.

The unbalancing load is placed at the generator's side, so the flexible bellows coupling may attenuate the fault signature in its spectra. For fault extraction, we can also apply the Thomson multitaper spectral estimates that are proven to be efficient in the case of weaker signals [26] and combine the beneficial properties of high resolution and low variance. Figure 6 displays the Thomson multitaper spectrum of the generator's current signal in which we can observe how the distinguished magnitudes are emphasized. This allows a fast, automatic extraction of the peaks. 


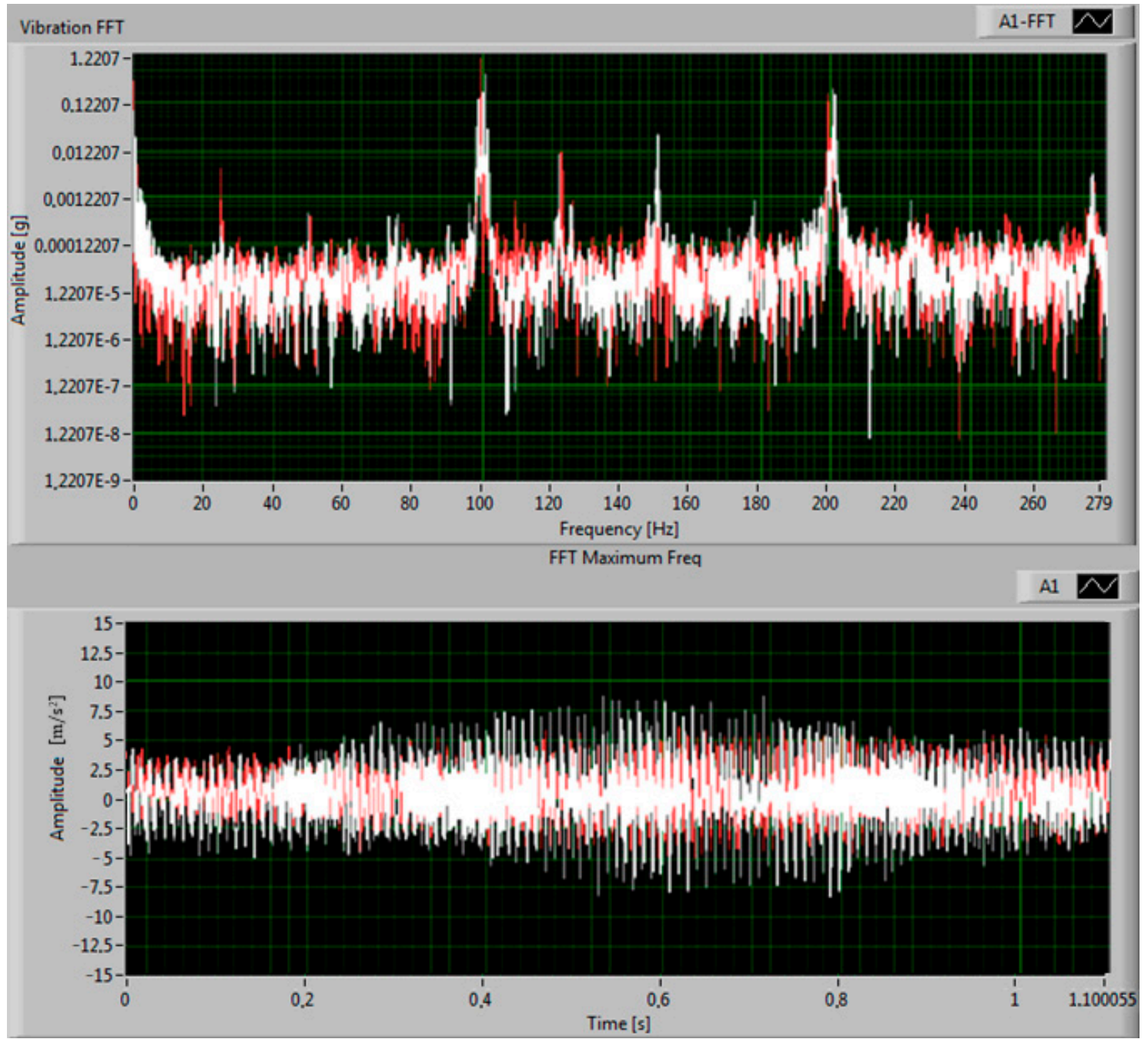

Figure 4. Fast Fourier Transform spectrum (upper chart) and time-domain signal (lower chart) of vibration data displayed online by the LabVIEW software during the measurement. A1 (white line) denotes the generator's vibration signal, and A2 (red line) stands for the motor's vibration signal.

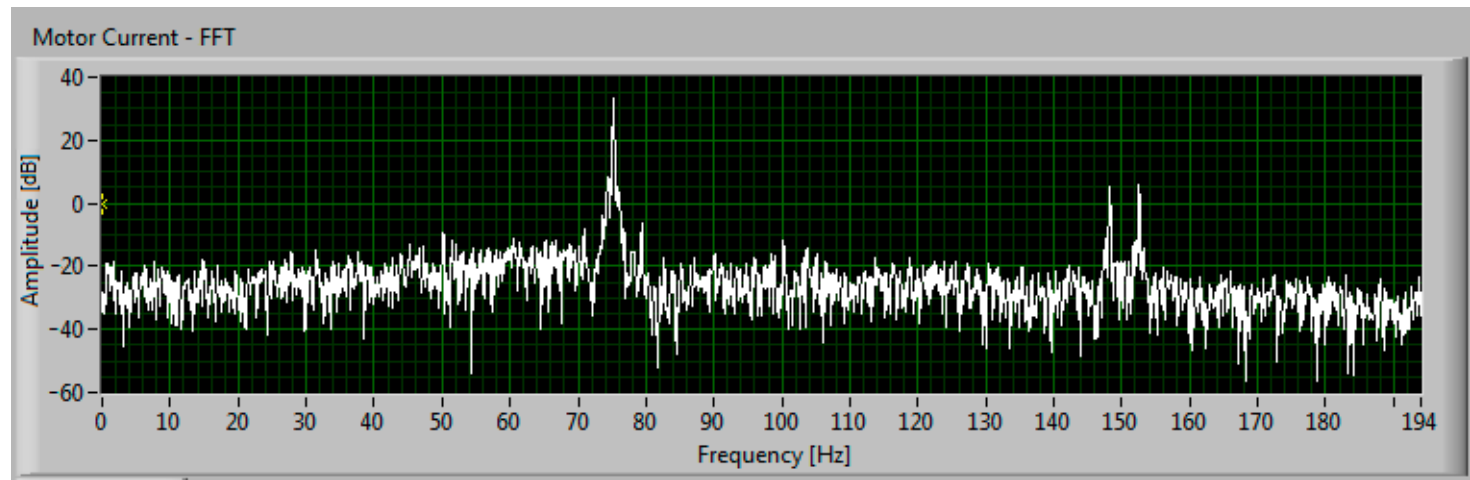

Figure 5. Fast Fourier Transform (FFT) spectra of the motor current (Im) stands for the motor's current component $a$. 


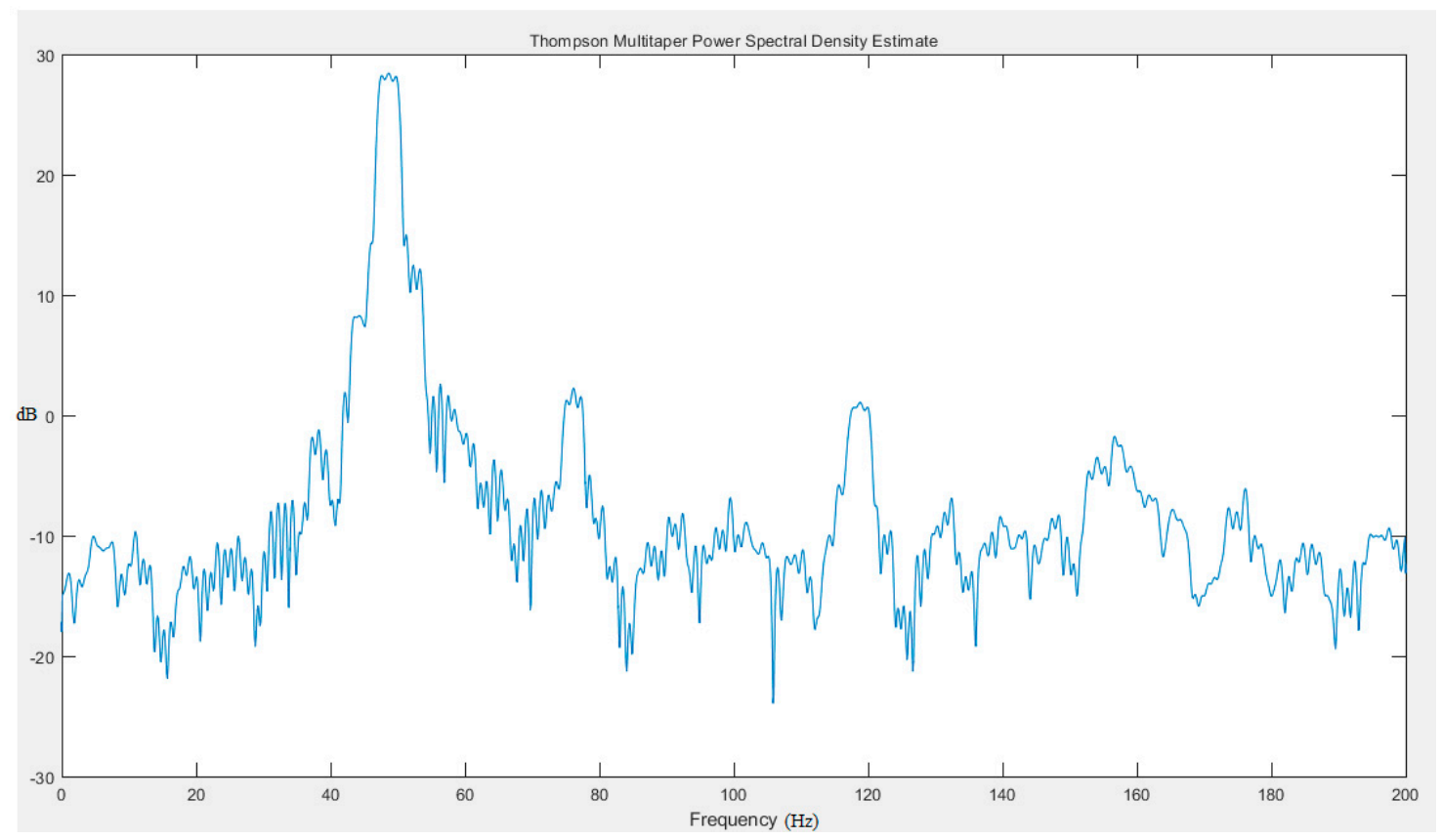

Figure 6. Multitaper power spectral density estimation of generator current signal for fault frequency magnitude detection.

The features carrying most of the information of interest are mainly in the frequency domain. However, we have inspected a few time-domain features also. The feature vector is composed of the magnitudes of the distinguished sideband frequencies and RMS variance frequencies from the spectra for all three phases of both machines. The time-domain features cover the form factor, kurtosis, and entropy deviation from the fault-free sample. The fault feature vector also includes the distance calculated between the observed signature and each pure signature associated with the identified fault [121-123].

It is worth noting that many attempts have been made with the purpose of improving performance through sophisticated feature extraction methods. In his seminal paper on recognition of diagnostic signals based on acoustic signals, Glowacz and Glowcz [124] have introduced a shortened method of frequencies selection. In [125], a novel method of selection of amplitudes of frequencies ratio 50-s frequency coefficient was introduced in order to build the feature vector. Recently, the new Method of Selection of Amplitudes of Frequency Ratio of 24\% Multiexpanded Filter $8 \mathrm{~Hz}$ and k-means clustering approach has been presented in [126]. This technique draws our attention to investigate the applicability of acoustic-based fault feature extraction techniques to ESA in our future work.

The dataset is built by synthetically adding a random number of ten to twenty of external disturbing frequency components for the faulty and fault free signals. Fifteen different samples are generated with random contaminating frequencies for all of the fault-free, multiple-fault, and single fault (unbalance or misalignment) cases and additionally the data collected by the accelerometers at both sides for the severity evaluation. The training set consists of 64 feature vectors, including the original ones and each of them containing 27 features.

In our qualitative models 'isUnbalance' and 'isMisalignment' (Table 2) are the fault label columns which consist of values $0(\mathrm{No})$ and 1 (Yes) corresponding to the presence of the symptom of a fault in a given sample. For the fault severity classifier, we have specified the labels according to the previously presented ISO standard [25] as 'Good', 'Satisfactory', 'Unsatisfactory', 'Unacceptable'. The dataset is divided into a training set $70 \%$ of the vectors to train the classifier and a testing set of $15 \%$ and $15 \%$ for validating the accuracy of the classifier on new data. When most of the samples have the same labels in the training set, the classifier will achieve a high accuracy value. In order to avoid such a bias, 
half of the dataset composed of samples including the fault features. Further metrics are applied for the proper evaluation of the performance.

Table 2. Structure of the dataset.

\begin{tabular}{ccccccc}
\hline id & Ia_motor & Ib_motor & $\ldots$ & isUnbalance & isMisalignm & Severity \\
\hline 0 & 0.687150 & 0.028560 & $\ldots$ & 0 & 1 & 'Good' \\
\hline 1 & 0.019699 & 0.388238 & $\ldots$ & 1 & 0 & 'Good' \\
\hline
\end{tabular}

\section{Results}

The experiments with three different algorithms are performed by applying the Python Scikit-multi-learn library, which offers various classification approaches that are suitable for predicting simultaneously multiple outputs. At first, a binarized Decision Tree has been implemented for predicting the labels. As a criterion, which defines the function to measure the quality of a split, both criteria for the Gini Index and entropy for Information Gain were used. We have also modified the maximum of tree depth in order to compare the performance using various maximum depths of the trees. Various tree models were also built, including and excluding the error attribute values. According to initial tests, we have found that applying the error feature attributes in the training does not result in significant improvement in the accuracy. The best accuracy score we have achieved is 0.7333. The accuracy score is not the most representative metric in the case of multi-label classification. Therefore, further metrics are applied. The results are collected in Table 3.

Table 3. Performance evaluation of the tested models.

\begin{tabular}{ccccc}
\hline Prediction Method and Label (0/1) & Precision & Recall & f1-Score \\
\hline Binarized & 0 & 0.79 & 0.88 & 0.83 \\
Decision Tree & 1 & 0.85 & 0.94 & 0.89 \\
Classifier Chain & 0 & 0.79 & 0.88 & 0.83 \\
& 1 & 0.78 & 1.00 & 0.88 \\
KNN & 0 & 0.76 & 0.76 & 0.76 \\
& 1 & 0.82 & 1.00 & 0.90 \\
\hline
\end{tabular}

The precision also shows the accuracy of the model by the ration of total predicted positive and the number of true positive ones. Recall or sensitivity is calculated by the number of true positives divided by the number of true positives plus the number of false negatives. The F1 score covers the weighted average of the sensitivity and precision values that are suitable to characterize the test performance. After, a Classifier Chain multi-label method using the Gaussian Naïve Bayes approach was tested. We found it to be more efficient. Its performance can be seen in Table 3. The Classifier Chain's score accuracy resulted in 0.8333 . Subsequently, we have tested the multi-label KNN method whose best percentage accuracy resulted in 0.7 after testing the algorithm with various $k$ values.

It can be seen from Table 3 that the classification performance has been the most enhanced by using Classifier Chains and KNN. The accuracy may be further improved by training a model with a larger training set and further tuning the algorithms. Its excellent pattern recognition capabilities can be effectively utilized for the fault classification of electrical machines in the presence of disturbing noises. The prediction performance of the parallel severity classification tree resulted in $99 \%$ accuracy because most of the vibration data is labeled 'good'.

\section{Discussion}

In modern industrial systems, complexity is increasing as multi-sensor network systems are expanding towards largescale systems. The intelligent solution of Electrical Signature Analysis allow simplifying the fault identification processes because it does not require a large number of sensors, 
which results in remarkable cost reduction, and supports sensorless and largescale technologies. Furthermore, a well-developed theoretical and practical methodology could serve as a basis for reliable remote diagnostic tasks of electrical machines, especially important diagnostics carried out in hazardous environments (for instance, in nuclear plants). The development of appropriate diagnosticprediction methods, which are capable of reliably and timely evaluating the health status of the system on the basis of representative parameters acquired directly or indirectly, is an important part of the modern electric drivetrain monitoring system. The state-of-health of a certain dynamic system and its possible initial failures can be addressed by a number of approaches published in the literature. The strengths and weaknesses of conventional fault diagnosis methods have already been proven. In recent years, diagnostics research has focused on the prediction algorithms that can identify the fault features of progressive malfunctions. As such algorithms are highly technology-dependent, it is important to define the method as a function of a large number of parameters of the dynamic system for fitting to the system under consideration, taking into account boundary conditions. Data-driven technologies aim such difficulties.

Fault classification methods have already been established for the investigation of the relations between the symptom and the fault feature. It is clear that binary relationships can be easily represented by such systems. Early versions of these algorithms are used rather for visualizing diagnostic reasoning. However, practical engineering problems demanded the development of new automatic methods that are able to deal with multiple fault scenarios and noisy or uncertain fault features. A possible solution is the extension of the most commonly applied classification methods. Recently, binary trees, Chain Classifiers, Neural Networks, and other multi-label and multi-class techniques were introduced in the literature. However, these algorithms need more development and improvement, especially in terms of robustness. In addition, the application of Machine Learning techniques on sensory data is still not well-established and requires the synergy of classical signal processing and intelligent data analysis. As a conclusion from all cases studied, the analysis of motor current signatures in combination with machine learning-based processing and evaluation algorithms is a viable methodology for fault detection and prediction in electrical machine and drive systems that has the following additional advantages; the measurement or monitoring does not interfere with the production process; it is well suited for any machine with speed, performance, and power; it is universal because it is able to detect the quality of electricity supply, disturbances, faults in a motor control, starter- and control-devices, the efficiency of the electric machine and its characteristics, errors in the electrical machine, plant-wide machine monitoring and its operating costs (energy consumption, repair, maintenance) meet the economy's expectations. The transfer of recent Machine Learning approaches to practical fault diagnosis problems of rotating electrical machines and drive systems may help to facilitate smart industrialization and intelligent modernization.

\section{Conclusions}

Automated electrical signature analysis-based fault detection and diagnosis of electrical machines is still an especially important issue in modern industrial applications. The recent data acquisition devices with high sample rate signal inputs have high levels of noise. The coupled machines may cause even heavy disturbances in the signal. A greater source of concern is the selection of the appropriate model and the unavailability of the dataset rich in fault signatures. With this in mind, this paper investigates the applicability of recent multi-label classification methods and suggests a new methodology for simultaneously diagnosing multiple faults and evaluating the fault severity under noisy conditions. Our study provides a new framework and strategy that has been tested on an experimental setup. According to the comparative investigations, we have found that the Classifier Chain strategy is the most suitable for issues of simultaneous noisy misalignment and unbalance fault. The fault signatures are composed of magnitudes of the fault and disturbing noise frequencies and some additional parameters. We have confirmed that relying on the knowledge of the physics of the fault event has twofold advantages. Obtaining the required training dataset is much shorter if we 
build a semi-synthetic database. A reliable model can be built by recording only a few measurements beforehand, which can be further refined during operation. On the other hand, the high dimension of attributes can be even simply reduced. Our investigations into this area are still ongoing and seem likely to confirm our hypothesis. To further our research, we intend to carry out more extensive investigations regarding the feature extraction techniques. For instance, extending recent findings of motor fault feature extraction, e.g., [126], based on acoustic signals to electrical signature analysis, also taking into account sensor fusion, can be undertaken.

Author Contributions: Principal investigator, lead author, writing, machine learning expertise, electric machines expertise, A.D.; data collection, data curation, data analysis, technical expertise, laboratory expertise, data acquisition system implementation, LabVIEW programming, M.G., N.N.; machine learning modeling expertise, writing, revision support, A.M., N.N.; electric machines expertise, conceptualization, supervision, resources, software, control and verification of the results, I.V., T.R.

Funding: This work has been supported by the project GINOP-2.3.4-15-2016-00003.

Conflicts of Interest: The authors declare no conflict of interest

\section{Nomenclature}

$\begin{array}{ll}\text { FDD } & \text { Fault detection and diagnosis } \\ \text { ML } & \text { Machine learning } \\ \text { MCSA } & \text { Motor current signature analysis } \\ \text { ESA } & \text { Electrical signature analysis } \\ \text { FDI } & \text { Detection and isolation } \\ \text { ANFIS } & \text { Adaptive neuro-fuzzy inference system } \\ \text { CART } & \text { Classification and regression Tree } \\ \text { CNN } & \text { Random forest classifier convolutional neural network } \\ \text { SVM } & \text { Support vector machine } \\ \text { KNN } & \text { k-nearest neighbors } \\ \text { PMSM } & \text { Permanent magnet synchronous machine } \\ \text { RF } & \text { Random Forest } \\ \text { ISO } & \text { International Organization for Standardization }\end{array}$

\section{References}

1. Dineva, A.; Mosavi, A.; Ardabili, S.; Vajda, I.; Shamshirband, S.; Rabczuk, T.; Chau, K.W. Review of soft computing models in design and control of rotating electrical machines. Energies 2019, 12, 1049. [CrossRef]

2. Jokanović, B.; Bebić, M.; Kartalović, N. The influence of combined strain and constructive solutions for stator insulation of rotating electrical machines on duration of their reliable exploitation. Int. J. Electr. Power Energy Syst. 2019, 110, 36-47. [CrossRef]

3. Roubache, L.; Boughrara, K.; Dubas, F.; Ibtiouen, R. Elementary subdomain technique for magnetic field calculation in rotating electrical machines with local saturation effect. COMPEL Int. J. Comput. Math. Electr. Electron. Eng. 2019, 38, 24-45. [CrossRef]

4. Boughrara, K.; Dubas, F.; Ibtiouen, R. 2-D exact analytical method for steady-state heat transfer prediction in rotating electrical machines. IEEE Trans. Magn. 2018, 54. [CrossRef]

5. Caruso, M.; Di Tommaso, A.O.; Miceli, R.; Rizzo, R. The use of slightly asymmetrical windings for rotating electrical machines. Int. Trans. Elecr. Energy Syst. 2018, 28. [CrossRef]

6. Kande, M.; Isaksson, A.J.; Thottappillil, R.; Taylor, N. Rotating electrical machine condition monitoring automation-A review. Machines 2017, 5, 24. [CrossRef]

7. Byerly, K.; Ohodnicki, P.R.; Moon, S.R.; Leary, A.M.; Keylin, V.; McHenry, M.E.; Simizu, S.; Beddingfield, R.; Yu, Y.; Feichter, G.; et al. Metal Amorphous Nanocomposite (MANC) Alloy Cores with Spatially Tuned Permeability for Advanced Power Magnetics Applications. JOM 2018, 70, 879-891. [CrossRef]

8. Fu, Y.; Huang, X.; Xu, Y.; Bai, C. Controllable inertial control strategy of rotating motor in DC distribution network. Dianli Zidonghua Shebei Electr. Power Autom. Equip. 2018, 38, 32-38. [CrossRef] 
9. Guerroudj, C.; Saou, R.; Boulayoune, A.; El-hadi Zaïm, M.; Moreau, L. Performance analysis of Vernier slotted doubly salient permanent magnet generator for wind power. Int. J. Hydrogen Energy 2017, 42, 8744-8755. [CrossRef]

10. Song, Z.; Li, Y.; Zhang, C.; Liu, Y. Rotating core loss model for motor considering skin effect and dynamic hysteresis effect. Nongye Gongcheng Xuebao 2019, 35, 74-80. [CrossRef]

11. Zhang, J.; Yu, H.; Chen, Q.; Hu, M. Dynamic characteristics and experiment analysis of a single phase permanent magnet linear generator for wave energy conversion. Diangong Jishu Xuebao 2013, 28, 110-116.

12. Mosavi, A.; Faizollahzadeh Ardabili, S.; Shamshirband, S. Demand prediction with machine learning models: State of the art and a systematic review of advances. 2019. Available online: https://eprints.qut.edu.au/129249/ (accessed on 20 November 2019). [CrossRef]

13. Akhtar, M.J.; Behera, R.K. Optimal design of stator and rotor slot of induction motor for electric vehicle applications. IET Electr. Syst. Transp. 2019, 9, 35-43. [CrossRef]

14. Deng, W.; Zuo, S. Electromagnetic vibration and noise of the permanent-magnet synchronous motors for electric vehicles: An overview. IEEE Trans. Transp. Electrif. 2019, 5, 59-70. [CrossRef]

15. Fan, Y.; Qu, G.; Tan, C.; Zhang, Q.; Wang, W. Design and analysis of a new five-phase dual-stator consequent-pole brushless hybrid excitation machine. IEEE Trans. Magn. 2019, 55. [CrossRef]

16. Ulu, C.; Korman, O.; Kömürgöz, G. Electromagnetic and thermal design/analysis of an induction motor for electric vehicles. Int. J. Mech. Eng. Robot. Res. 2019, 8, 239-245. [CrossRef]

17. Mosavi, A.; Salimi, M.; Faizollahzadeh Ardabili, S.; Rabczuk, T.; Shamshirband, S.; Varkonyi-Koczy, A.R. State of the art of machine learning models in energy systems, a systematic review. Energies 2019, 12, 1301. [CrossRef]

18. Baranyai, M.; Mosavi, A.; Vajda, I.; Varkonyi-Koczy, A.R. Optimal Design of Electrical Machines: State of the Art Survey. In Proceedings of the International Conference on Global Research and Education, Iasi, Romania, 25-28 September 2017; pp. 209-216.

19. Aljehaimi, A.M.; Pillay, P. Operating Envelopes of the Variable-Flux Machine with Positive Reluctance Torque. IEEE Trans. Transp. Electrif. 2018, 4, 707-719. [CrossRef]

20. Catuogno, G.R.; Garcia, G.O. Conversion of Three-phase Commercial Machines into Six- phase Machines for Didactic and Research Purposes. IEEE. Lat. Am. Trans. 2018, 16, 467-475. [CrossRef]

21. Morozov, A.; Humphries, K.; Zou, T.; Rahman, T.; Angeles, J. Design, Analysis, and Optimization of a Multi-Speed Powertrain for Class-7 Electric Trucks. SAE Int. J. Altern. Powertrains 2018, 7. [CrossRef]

22. Palanivel, A.; Padmanabhan, S. Software-based performance estimation and real-time thermal analysis of brushless direct current motor with corroded permanent magnets. Comput. Electr. Eng. 2018, 71, 938-952. [CrossRef]

23. Praveenkumar, T.; Saimurugan, M.; Ramachandran, K.I. Comparison of vibration, sound and motor current signature analysis for detection of gear box faults. Int. J. Progn. Health Manag. 2017, 8, 132-151.

24. Bessous, N.; Sbaa, S.; Megherbi, A.C. Mechanical fault detection in rotating electrical machines using MCSA-FFT and MCSA-DWT techniques. Bull. Pol. Acad. Sci. Tech. Sci. 2019, 67, 571-582. [CrossRef]

25. Corne, B.; Vervisch, B.; Derammelaere, S.; Knockaert, J.; Desmet, J. Emulating single point bearing faults with the use of an active magnetic bearing. IET Sci. Meas. Technol. 2018, 12, 39-48. [CrossRef]

26. Glowacz, A.; Glowacz, W.; Glowacz, Z.; Kozik, J.; Gutten, M.; Korenciak, D.; Khan, Z.F.; Irfan, M.; Carletti, E. Fault diagnosis of three phase induction motor using current signal, MSAF-Ratio15 and selected classifiers. Arch. Metall. Mater. 2017, 62, 2413-2419. [CrossRef]

27. Martín-Díaz, I.; Duque-Perez, O.; Romero-Troncoso, R.; Morinigo-Sotelo, D. Supervised diagnosis of induction motor faults: A proposed methodology for an improved performance evaluation. In Proceedings of the IEEE 10th International Symposium on Diagnostics for Electrical Machines, Power Electronics and Drives, Guarda, Portugal, 1-4 September 2015; pp. 359-365.

28. Irhoumah, M.; Pusca, R.; Lefevre, E.; Mercier, D.; Romary, R.; Demian, C. Information Fusion with Belief Functions for Detection of Interturn Short-Circuit Faults in Electrical Machines Using External Flux Sensors. IEEE Trans. Ind. Electron. 2018, 65, 2642-2652. [CrossRef]

29. Lopez-Perez, D.; Antonino-Daviu, J. Application of Infrared Thermography to Failure Detection in Industrial Induction Motors: Case Stories. IEEE Trans. Ind. Appl. 2017, 53, 1901-1908. [CrossRef]

30. Ma, Y.; $\mathrm{Wu}, \mathrm{X}$. Discriminant sparse and collaborative preserving embedding for bearing fault diagnosis. Neurocomputing 2018, 313, 259-270. [CrossRef] 
31. Sapena-Bano, A.; Martinez-Roman, J.; Puche-Panadero, R.; Pineda-Sanchez, M.; Perez-Cruz, J.; Riera-Guasp, M. Induction machine model with space harmonics for fault diagnosis based on the convolution theorem. Int. J. Electr. Power Energy Syst. 2018, 100, 463-481. [CrossRef]

32. Antonino-Daviu, J.; Popaleny, P. Detection of Induction Motor Coupling Unbalanced and Misalignment Via Advanced Transient Current Signature Analysis. In Proceedings of the 2018 XIII International Conference on Electrical Machines (ICEM), Alexandroupoli, Greece, 3-6 September 2018; pp. 2359-2364.

33. Bessous, N.; Chemsa, A.; Sbaa, S. New Vision about the Mixed Eccentricity Fault Causes in Induction Motors and its relationship with the Rolling Element Bearing Faults: Analytical model dedicated to the REB faults. In Proceedings of the 2018 International Conference on Communications and Electrical Engineering (ICCEE), El Oued, Algeria, 17-18 December 2018.

34. Brandt, M.; Gutten, M.; Koltunowicz, T.; Zukowski, P. Analysis of winding fault in electric machines by frequency method. In Proceedings of the 2018 ELEKTRO, Mikulov, Czech Republic, 21-23 May 2018; pp. $1-4$.

35. Nikita, T.; Manickavasagam, K.; Sachin, S. Magnetostriction analysis on doubly fed induction generator under normal and low voltage ride through (LVRT) condition. In Proceedings of the 2017 International Conference on Technological Advancements in Power and Energy (TAP Energy), Kollam, India, 21-23 December 2017; pp. 1-5.

36. Ugale, R.T.; Gore, S.N.; Chaudhari, B.N. Web based remote and locally operated all in one electrical machine laboratory with data acquisition, fault diagnosis and protection. In Proceedings of the 2018 XIII International Conference on Electrical Machines (ICEM), Alexandroupoli, Greece, 3-6 September 2018; pp. 1979-1985.

37. Ullah, S.; McDonald, S.P.; Martin, R.; Benarous, M.; Atkinson, G.J. A permanent magnet assist, segmented rotor, switched reluctance drive for fault tolerant aerospace applications. IEEE Trans. Ind. Appl. 2019, 55, 298-305. [CrossRef]

38. Wang, X.B.; Zhang, X.; Li, Z.; Wu, J. Ensemble extreme learning machines for compound-fault diagnosis of rotating machinery. Knowl. Syst. 2019. [CrossRef]

39. Kankar, P.K.; Sharma, S.C.; Harsha, S.P. Fault diagnosis of ball bearings using machine learning methods. Expert Syst. Appl. 2011, 38, 1876-1886. [CrossRef]

40. Pöyhönen, S.; Negrea, M.; Jover, P.; Arkkio, A.; Hyötyniemi, H. Numerical magnetic field analysis and signal processing for fault diagnostics of electrical machines. COMPEL Int. J. Comput. Math. Electr. Electron. Eng. 2003, 22, 969-981. [CrossRef]

41. Ijadi Maghsoodi, A.; Ijadi Maghsoodi, A.; Mosavi, A.; Rabczuk, T.; Zavadskas, E. Renewable energy technology selection problem using integrated h-swara-multimoora approach. Sustainability 2018, 10, 4481. [CrossRef]

42. Papoutsidakis, M.; Kalovrektis, K.; Drosos, C.; Stamoulis, G. Design of an Autonomous Robotic Vehicle for Area Mapping and Remote Monitoring. Int. J. Comput. Appl. 2017, 167, 36-41. [CrossRef]

43. Zekveld, M.; Hancke, G.P. Vibration Condition Monitoring Using Machine Learning. In Proceedings of the IECON 2018-44th Annual Conference of the IEEE Industrial Electronics Society, Washington, DC, USA, 21-23 October 2018; pp. 4742-4747.

44. Aydemir, G. Deep learning based spectrum compression algorithm for rotating machinery condition monitoring. In Proceedings of the ASME 2018 Conference on Smart Materials, Adaptive Structures and Intelligent Systems, San Antonio, TX, USA, 10-12 September 2018.

45. Dos Santos, T.; Ferreira, F.J.T.E.; Pires, J.M.; Damasio, C. Stator winding short-circuit fault diagnosis in induction motors using random forest. In Proceedings of the 2017 IEEE International Electric Machines and Drives Conference (IEMDC), Miami, FL, USA, 21-24 May 2017.

46. Ferreira, J.G.; Warzecha, A. An application of machine learning approach to fault detection of a synchronous machine. In Proceedings of the 2017 International Symposium on Electrical Machines (SME), Naleczow, Poland, 18-21 June 2017.

47. Senanayaka, J.S.L.; Kandukuri, S.T.; Khang, H.V.; Robbersmyr, K.G. Early detection and classification of bearing faults using support vector machine algorithm. In Proceedings of the 2017 IEEE Workshop on Electrical Machines Design, Control and Diagnosis (WEMDCD), Nottingham, UK, 20-21 April 2017; pp. 250-255.

48. Senanayaka, J.S.L.; Van Khang, H.; Robbersmyr, K.G. Towards online bearing fault detection using envelope analysis of vibration signal and decision tree classification algorithm. In Proceedings of the 
2017 20th International Conference on Electrical Machines and Systems (ICEMS), Sydney, NSW, Australia, 11-14 August 2017.

49. Zhang, J.; Zhan, W.; Ehsani, M. On-line fault diagnosis of electric machine based on the Hidden Markov Model. In Proceedings of the 2016 IEEE Transportation Electrification Conference and Expo (ITEC), Dearborn, MI, USA, 27-29 June 2016.

50. Abid, F.B.; Zgarni, S.; Braham, A. Distinct bearing faults detection in induction motor by a hybrid optimized SWPT and aiNet-DAG SVM. IEEE Trans. Energy Convers. 2018, 33, 1692-1699. [CrossRef]

51. Giantomassi, A.; Ferracuti, F.; Iarlori, S.; Ippoliti, G.; Longhi, S. Signal Based Fault Detection and Diagnosis for Rotating Electrical Machines: Issues and Solutions. In Studies in Fuzziness and Soft Computing; Springer: Berlin/Heidelberg, Germany, 2015; Volume 319, pp. 275-309.

52. Afrasiabi, S.; Afrasiabi, M.; Parang, B.; Mohammadi, M. Real-Time Bearing Fault Diagnosis of Induction Motors with Accelerated Deep Learning Approach. In Proceedings of the 2019 10th International Power Electronics, Drive Systems and Technologies Conference (PEDSTC), Shiraz, Iran, 12-14 February 2019; pp. 155-159.

53. He, D.; Fahimi, B. Power management of a self-powered multi-parameter wireless sensor for IoT application. In Proceedings of the 2018 IEEE Applied Power Electronics Conference and Exposition (APEC), San Antonio, TX, USA, 4-8 March 2018; pp. 1380-1385.

54. Martin-Diaz, I.; Morinigo-Sotelo, D.; Duque-Perez, O.; Romero-Troncoso, R.J. An Experimental Comparative Evaluation of Machine Learning Techniques for Motor Fault Diagnosis under Various Operating Conditions. IEEE Trans. Ind. Appl. 2018, 54, 2215-2224. [CrossRef]

55. Shamshirband, S.; Rabczuk, T.; Chau, K.W. A Survey of Deep Learning Techniques: Application in Wind and Solar Energy Resources. IEEE Access 2019, 7, 164650-164666. [CrossRef]

56. Senanayaka, J.S.L.; Van Khang, H.; Robbersmyr, K.G. Online Fault Diagnosis System for Electric Powertrains Using Advanced Signal Processing and Machine Learning. In Proceedings of the 2018 XIII International Conference on Electrical Machines (ICEM), Alexandroupoli, Greece, 3-6 September 2018; pp. 1932-1938.

57. Chahine, K. Rotor fault diagnosis in induction motors by the matrix pencil method and support vector machine. Int. Trans. Elecr. Energy Syst. 2018, 28. [CrossRef]

58. Kao, I.H.; Wang, W.J.; Lai, Y.H.; Perng, J.W. Analysis of Permanent Magnet Synchronous Motor Fault Diagnosis Based on Learning. IEEE Trans. Instrum. Meas. 2019, 68, 310-324. [CrossRef]

59. Mendonça, P.L.; Bonaldi, E.L.; de Oliveira, L.E.L.; Lambert-Torres, G.; Borges da Silva, J.G.; Borges da Silva, L.E.; Salomon, C.P.; Santana, W.C.; Shinohara, A.H. Detection and modelling of incipient failures in internal combustion engine driven generators using Electrical Signature Analysis. Electr. Power Syst. Res. 2017, 149, 30-45. [CrossRef]

60. Cabal-Yepez, E.; Romero-Troncoso, R.; Garcia-Perez, A.; Osornio-Rios, R. Single-parameter fault identification through information entropy analysis at the startup-transient current in induction motors. Electr. Power Syst. Res. 2012, 89, 64-69. [CrossRef]

61. Dehghani, M.; Riahi-Madvar, H.; Hooshyaripor, F.; Mosavi, A.; Shamshirband, S.; Zavadskas, E.K.; Chau, K.W. Prediction of hydropower generation using grey wolf optimization adaptive neuro-fuzzy inference system. Energies 2019, 12, 289. [CrossRef]

62. Delpha, C.; Diallo, D.; Al Samrout, H.; Moubayed, N. Multiple incipient fault diagnosis in three-phase electrical systems using multivariate statistical signal processing. Eng. Appl. Artif. Intell. 2018, 73, 68-79. [CrossRef]

63. Vas, P. Parameter Estimation, Condition Monitoring, and Diagnosis of Electrical Machines; Oxford University Press: Oxford, UK, 1993; Volume 27.

64. Tidriri, K.; Tiplica, T.; Chatti, N.; Verron, S. A generic framework for decision fusion in fault detection and diagnosis. Eng. Appl. Artif. Intell. 2018, 71,73-86. [CrossRef]

65. Delgado-Arredondo, P.A.; Morinigo-Sotelo, D.; Osornio-Rios, R.A.; Avina-Cervantes, J.G.; Rostro-Gonzalez, H.; de Jesus Romero-Troncoso, R. Methodology for fault detection in induction motors via sound and vibration signals. Mech. Syst. Signal Process. 2017, 83, 568-589. [CrossRef]

66. Serdio, F.; Lughofer, E.; Pichler, K.; Pichler, M.; Buchegger, T.; Efendic, H. Fuzzy fault isolation using gradient information and quality criteria from system identification models. Inf. Sci. 2015, 316, 18-39. [CrossRef] 
67. Serdio, F.; Lughofer, E.; Zavoianu, A.-C.; Pichler, K.; Pichler, M.; Buchegger, T.; Efendic, H. Improved fault detection employing hybrid memetic fuzzy modeling and adaptive filters. Appl. Soft Comput. 2017, 51, 60-82. [CrossRef]

68. Jafari, H.; Poshtan, J. Fault detection and isolation based on fuzzy-integral fusion approach. IET Sci. Meas. Technol. 2019, 13, 296-302. [CrossRef]

69. Chen, Z.; Li, X.; Yang, C.; Peng, T.; Yang, C.; Karimi, H.R.; Gui, W. A data-driven ground fault detection and isolation method for main circuit in railway electrical traction system. ISA Trans. 2019, 87, 264-271. [CrossRef]

70. Jung, D.; Frisk, E. Residual selection for fault detection and isolation using convex optimization. Automatica 2018, 97, 143-149. [CrossRef]

71. Jung, D.; Sundstrom, C. A Combined Data-Driven and Model-Based Residual Selection Algorithm for Fault Detection and Isolation. IEEE Trans. Control. Syst. Technol 2019, 27, 616-630. [CrossRef]

72. Kannan, R.; Solai Manohar, S.; Senthil Kumaran, M. Nominal features-based class specific learning model for fault diagnosis in industrial applications. Comput. Ind. Eng. 2018, 116, 163-177. [CrossRef]

73. Na, W.; Park, C.; Lee, S.; Yu, S.; Lee, H. Sensitivity-based fault detection and isolation algorithm for road vehicle chassis sensors. Sensors 2018, 18, 2720. [CrossRef] [PubMed]

74. El Bakri, A.; Koumir, M.; Boumhidi, I. Extreme learning machine-based non-linear observer for fault detection and isolation of wind turbine. Aust. J. Electr. Electron. Eng. 2019, 16, 12-20. [CrossRef]

75. Sarwar, M.; Mehmood, F.; Abid, M.; Khan, A.Q.; Gul, S.T.; Khan, A.S. High impedance fault detection and isolation in power distribution networks using support vector machines. J. King Saud Univ. Eng. Sci. 2019. [CrossRef]

76. Shahnazari, H.; Mhaskar, P.; House, J.M.; Salsbury, T.I. Modeling and fault diagnosis design for HVAC systems using recurrent neural networks. Comput. Chem. Eng. 2019, 189-203. [CrossRef]

77. Yang, J.; Guo, Y.; Zhao, W. Long short-term memory neural network based fault detection and isolation for electro-mechanical actuators. Neurocomputing 2019. [CrossRef]

78. Abderrahmane, M.; Mohammed, B. Fault diagnosis of a wind turbine benchmark via statistical and support vector machine. Int. J. Eng. Res. Afr. 2018, 37, 29-42. [CrossRef]

79. Ait-Izem, T.; Harkat, M.F.; Djeghaba, M.; Kratz, F. On the application of interval PCA to process monitoring: A robust strategy for sensor FDI with new efficient control statistics. J. Process. Control. 2018, 63, $29-46$. [CrossRef]

80. Fazai, R.; Ben Abdellafou, K.; Said, M.; Taouali, O. Online fault detection and isolation of an AIR quality monitoring network based on machine learning and metaheuristic methods. Int. J. Adv. Manuf. Technol. 2018, 99, 2789-2802. [CrossRef]

81. Khorasgani, H.; Biswas, G. A methodology for monitoring smart buildings with incomplete models. Appl. Soft Comput. J. 2018, 71, 396-406. [CrossRef]

82. Lindahl, P.A.; Green, D.H.; Bredariol, G.; Aboulian, A.; Donnal, J.S.; Leeb, S.B. Shipboard Fault Detection Through Nonintrusive Load Monitoring: A Case Study. IEEE Sens. J. 2018, 18, 8986-8995. [CrossRef]

83. Mohamed Syed Ali, A. Helmet deduction using image processing. Indones. J. Electr. Eng. Comput. Sci. 2018, 9, 342-344. [CrossRef]

84. Zhang, D.; Qian, L.; Mao, B.; Huang, C.; Huang, B.; Si, Y. A Data-Driven Design for Fault Detection of Wind Turbines Using Random Forests and XGboost. IEEE Access 2018, 6, 21020-21031. [CrossRef]

85. Cheng, F.; Wang, J.; Qu, L.; Qiao, W. Rotor current-based fault diagnosis for DFIG wind turbine drivetrain gearboxes using frequency analysis and a deep classifier. IEEE Trans. Ind. Appl. 2018, 54, 1062-1071. [CrossRef]

86. Mosavi, A.; Faizollahzadeh ardabili, S.; Várkonyi-Kóczy, A.R. List of Deep Learning Models. Preprints 2019, 2019080152. [CrossRef]

87. Gao, Z.; Sheng, S. Real-time monitoring, prognosis, and resilient control for wind turbine systems. Renew. Energy 2018, 116, 1-4. [CrossRef]

88. Zhu, Y.; Zhu, C.; Song, C.; Li, Y.; Chen, X.; Yong, B. Improvement of reliability and wind power generation based on wind turbine real-time condition assessment. Int. J. Electr. Power Energy Syst. 2019, 113, 344-354. [CrossRef] 
89. Vigneshkumar, S.; Shankar, V.K.; Krishna, P.N.; Supriya, P. Fault Detection in Gearbox Using Motor Electrical Signature Analysis. In Proceedings of the 2018 9th International Conference on Computing, Communication and Networking Technologies (ICCCNT), Bangalore, India, 10-12 July 2018; pp. 1-6.

90. Yang, B.-S.; Oh, M.-S.; Tan, A.C.C. Fault diagnosis of induction motor based on decision trees and adaptive neuro-fuzzy inference. Expert Syst. Appl. 2009, 36, 1840-1849.

91. Patel, R.K.; Giri, V. Feature selection and classification of mechanical fault of an induction motor using random forest classifier. Perspect. Sci. 2016, 8, 334-337. [CrossRef]

92. Wardle, F.P. Vibration forces produced by waviness of the rolling surfaces of thrust loaded ball bearings Part 1: Theory. Proc. Inst. Mech. Eng. Part C J. Mech. Eng. Sci. 1988, 202, 305-312. [CrossRef]

93. Lynagh, N.; Rahnejat, H.; Ebrahimi, M.; Aini, R. Bearing induced vibration in precision high speed routing spindles. Int. J. Mach. Tools Manuf. 2000, 40, 561-577. [CrossRef]

94. Zimroz, R.; Bartelmus, W.; Barszcz, T.; Urbanek, J. Diagnostics of bearings in presence of strong operating conditions non-stationarity-A procedure of load-dependent features processing with application to wind turbine bearings. Mech. Syst. Signal Process. 2014, 46, 16-27. [CrossRef]

95. Chen, J.; Pan, J.; Li, Z.; Zi, Y.; Chen, X. Generator bearing fault diagnosis for wind turbine via empirical wavelet transform using measured vibration signals. Renew. Energy 2016, 89, 80-92. [CrossRef]

96. Teng, W.; Ding, X.; Zhang, X.; Liu, Y.; Ma, Z. Multi-fault detection and failure analysis of wind turbine gearbox using complex wavelet transform. Renew. Energy 2016, 93, 591-598. [CrossRef]

97. Muralidharan, V.; Sugumaran, V. Feature extraction using wavelets and classification through decision tree algorithm for fault diagnosis of mono-block centrifugal pump. Measurement 2013, 46, 353-359. [CrossRef]

98. Wen, L.; Gao, L.; Li, X.; Wang, L.; Zhu, J. A Jointed Signal Analysis and Convolutional Neural Network Method for Fault Diagnosis. Procedia CIRP 2018, 72, 1084-1087. [CrossRef]

99. Tsoumakas, G.; Katakis, I. Multi-label classification: An overview. Int. J. Data Warehous. Min. (IJDWM) 2007, 3, 1-13. [CrossRef]

100. Herrera, F.; Charte, F.; Rivera, A.J.; Del Jesus, M.J. Multilabel classification. In Multilabel Classification; Springer: Berlin/Heidelberg, Germany, 2016; pp. 17-31.

101. Read, J.; Pfahringer, B.; Holmes, G. Multi-label classification using ensembles of pruned sets. In Proceedings of the 8th IEEE International Conference on Data Mining, Pisa, Italy, 15-19 December 2008; pp. 995-1000.

102. Read, J.; Pfahringer, B.; Holmes, G.; Frank, E. Classifier chains for multi-label classification. Mach. Learn. 2011, 85, 333. [CrossRef]

103. Fu, H.; Cheng, J.; Xu, Y.; Wong, D.W.K.; Liu, J.; Cao, X. Joint optic disc and cup segmentation based on multi-label deep network and polar transformation. IEEE Trans. Med. Imaging 2018, 37, 1597-1605. [CrossRef] [PubMed]

104. Rauber, T.W.; Mello, L.H.; Rocha, V.F.; Varejão, F.M. Multi-label fault classification experiments in a chemical process. In Proceedings of theIEEE Brazilian Conference on Intelligent Systems, Sao Paulo, Brazil, 18-22 October 2014; pp. 265-270.

105. Cakir, E.; Heittola, T.; Huttunen, H.; Virtanen, T. Polyphonic sound event detection using multi label deep neural networks. In Proceedings of the 2015 International Joint Conference on Neural Networks (IJCNN), Killarney, Ireland, 12-17 July 2015; pp. 1-7.

106. Yang, X.; Song, J.; Wu, X.; Xie, L.; Liu, X.; Li, G. Identification of unhealthy Panax notoginseng from different geographical origins by means of multi-label classification. Spectrochim. Acta Part A Mol. Biomol. Spectrosc. 2019, 222, 117243. [CrossRef] [PubMed]

107. Hsu, C.-W.; Chang, C.-C.; Lin, C.-J. A Practical Guide to Support Vector Classification; National Taiwan University of Science and Technology (Taiwan Tech): Taipei City, Taiwan, 2003.

108. Dudani, S.A. The distance-weighted k-nearest-neighbor rule. IEEE Trans. Syst. Man Cybern. 1976, SMC-6, 325-327. [CrossRef]

109. Basu, K.; Debusschere, V.; Bacha, S.; Maulik, U.; Bondyopadhyay, S. Nonintrusive load monitoring: A temporal multilabel classification approach. IEEE Trans. Ind. Inf. 2014, 11, 262-270. [CrossRef]

110. Domeniconi, C.; Gunopulos, D. Adaptive nearest neighbor classification using support vector machines. In Proceedings of the Advances in Neural Information Processing Systems, Vancouver, BC, Canada, 3-8 December 2001; pp. 665-672.

111. Keskes, H.; Braham, A.; Lachiri, Z. Broken rotor bar diagnosis in induction machines through stationary wavelet packet transform and multiclass wavelet SVM. Electr. Power Syst. Res. 2013, 97, 151-157. [CrossRef] 
112. Imandoust, S.B.; Bolandraftar, M. Application of k-nearest neighbor (knn) approach for predicting economic events: Theoretical background. Int. J. Eng. Res. Appl. 2013, 3, 605-610.

113. Hu, L.-Y.; Huang, M.-W.; Ke, S.-W.; Tsai, C.-F. The distance function effect on k-nearest neighbor classification for medical datasets. SpringerPlus 2016, 5, 1304. [CrossRef]

114. Torabi, M.; Hashemi, S.; Saybani, M.R.; Shamshirband, S.; Mosavi, A. A Hybrid clustering and classification technique for forecasting short-term energy consumption. Environ. Prog. Sustain. Energy 2019, 38, 66-76. [CrossRef]

115. Gómez, D.; Rojas, A. An empirical overview of the no free lunch theorem and its effect on real-world machine learning classification. Neural Comput. 2016, 28, 216-228. [CrossRef]

116. Wolpert, D.H.; Macready, W.G. No free lunch theorems for optimization. IEEE Trans. Evolut. Comput. 1997, 1, 67-82. [CrossRef]

117. Galar, M.; Fernandez, A.; Barrenechea, E.; Bustince, H.; Herrera, F. A review on ensembles for the class imbalance problem: Bagging-, boosting-, and hybrid-based approaches. IEEE Trans. Syst. Man Cybern. Part C (Appl. Rev.) 2011, 42, 463-484. [CrossRef]

118. Polikar, R. Ensemble based systems in decision making. IEEE Circuit. Syst. Mag. 2006, 6, 21-45. [CrossRef]

119. Stack, J.R.; Habetler, T.G.; Harley, R.G. Effects of machine speed on the development and detection of rolling element bearing faults. IEEE Power Electr. Lett. 2003, 1, 19-21. [CrossRef]

120. Skipp, B. Ground vibration-Codes and standards. In Ground Dynamics and Man-Made Processes; The Institution of Civil Engineers: Glasgow, UK, 1998; pp. 29-41.

121. Liu, H.; Motoda, H. Feature Extraction, Construction and Selection: A Data Mining Perspective; Springer Science \& Business Media: Berlin, Germany, 1998; Volume 453.

122. Holcsik, P.; Pálfi, J.; Čonka, Z.; Avornicului, M. A Theoretical Approach to The Implementation of Low-Voltage Smart Switch Boards. Acta Polytech. Hung. 2019, 16, 123-149.

123. Pálfi, J.; Takács, M.; Holcsik, P.; Mitrik, Z. Determination of the fault identification accuracy in LV networks using the Fuzzy method. In Proceedings of the 2016 IEEE International Conference on Systems, Man, and Cybernetics, Budapest, Hungary, 9-12 October 2016; pp. 2756-2761.

124. Glowacz, A.; Głowacz, Z. Recognition of rotor damages in a DC motor using acoustic signals. Bull. Pol. Acad. Sci. Tech. Sci. 2017, 65, 187-194. [CrossRef]

125. Glowacz, A.; Glowacz, W. Vibration-Based Fault Diagnosis of Commutator Motor. Shock Vib. $2018,2018$. [CrossRef]

126. Glowacz, A. Acoustic fault analysis of three commutator motors. Mech. Syst. Signal Process. 2019, $133,106226$. [CrossRef]

(C) 2019 by the authors. Licensee MDPI, Basel, Switzerland. This article is an open access article distributed under the terms and conditions of the Creative Commons Attribution (CC BY) license (http://creativecommons.org/licenses/by/4.0/). 